\title{
Raising consumer awareness of portion size distortion on the island of Ireland
}

\author{
L. K. Pourshahidi ${ }^{1}$, G. P. Faulkner ${ }^{1}$, M. Spence ${ }^{2}$, S. O’Brien ${ }^{3}$, M. A. Kerr ${ }^{1}$, T. A. McCrorie ${ }^{1}$, \\ J. M. W. Wallace ${ }^{1}$ and M. B. E. Livingstone ${ }^{1}$ \\ ${ }^{1}$ Northern Ireland Centre for Food and Health, University of Ulster, Coleraine, BT52 1SA, UK, ${ }^{2}$ School of Biological \\ Sciences, Queen's University Belfast, BT9 5AG, UK and ${ }^{3}$ Institute of Food and Health, University College Dublin, \\ Belfield, Dublin 4, Republic of Ireland
}

Larger food portion sizes (PS) have been identified as one of the many environmental factors associated with the increase in obesity in Ireland $^{(1)}$. Larger PS can both incite over-eating ${ }^{(2,3)}$ and contribute to a distorted perception of appropriate PS ${ }^{(4)}$. The aim of the current study was to develop and evaluate a computer-based tool to raise awareness of food PS distortion among Irish consumers.

An online tool was developed using a web-based survey builder (SurveyMonkey ${ }^{\circledR}$ ). Respondents were asked to estimate the number of calories in the larger PS compared to the smaller PS for five eating occasions, using foods commonly consumed by Irish adults. Additional questions included demographics and current perceptions of food PS. Feedback on the tool was given in terms of its usefulness for raising awareness of large PS, rating its ease of use (not easy to very easy) and the content (very poor to very good). Adults (18-64 years), living on the island of Ireland were invited to take part in the study via email distribution lists and social networking sites.

A total of 1,032 adults completed all questions. The group were mainly female (77.8\%); aged 18-30 years (57.8\%); following no special diet $(72.4 \%)$. The majority of respondents felt that compared to 10 years ago, PS were bigger in fast food outlets, restaurants and supermarkets, however PS were perceived to be the same in the home.

\begin{tabular}{|c|c|c|c|c|c|c|}
\hline & \multicolumn{2}{|c|}{ All } & \multicolumn{2}{|c|}{ Females } & \multicolumn{2}{|c|}{ Males } \\
\hline & $n$ & $\%$ & $n$ & $\%$ & $n$ & $\%$ \\
\hline \multicolumn{7}{|c|}{ Has this quiz increased your awareness of large PS?* } \\
\hline Yes & 659 & 63.9 & 515 & 64.1 & 144 & 62.9 \\
\hline No, I was already aware & 301 & 29.2 & 246 & 30.6 & 55 & 24.0 \\
\hline No, it is not important to me & 49 & 4.7 & 28 & 3.5 & 21 & 9.2 \\
\hline Not sure & 23 & 2.2 & 14 & 1.7 & 9 & 3.9 \\
\hline
\end{tabular}

* Significant difference between the categories of awareness in all respondents, and within each gender $(P<0.001$

Chi-square)

The tool significantly increased awareness of larger portion sizes for the majority of respondents. Overall, only fifteen (1.5\%) of respondents correctly estimated the larger calorie content at all five eating occasions, with the majority $(63.8 \%)$ correctly estimating the calories at two or three eating occasions. Despite rating the ease of use and content of the tool highly (mean rating 7.8 and 9.3 out of 10 , respectively), $21.4 \%$ of respondents reporting an increase in awareness, indicated that they were not likely to change their PS after using the tool.

In this study, the online tool was effective in raising awareness of food PS distortion and the tool was well received by Irish adults. However, the complex interaction between raising awareness and promoting behaviour change is highlighted.

This is based upon works supported by safefood, the Food Safety Promotion Board, under Grant No. 07-2010. Ethical approval was obtained from the Biomedical Sciences Ethics Filter Committee at the University of Ulster.

1. McCarthy SN, Robson PJ, Livingstone MBE et al. (2006) Int J Obes 30, 993-1002.

2. Rolls BJ, Morris EL \& Roe LS (2002) Am J Clin Nutr 76, 1207-13.

3. Kelly MT, Wallace JMW, Robson PJ et al. (2009) Br J Nutr 102, 470-7.

4. Levitsky DA \& Youn T (2004) J Nut 134, 2546-9. 